\title{
IMPLANTAÇÃO DA DISCIPLINA ALFABETIZAÇÃO NO CURSO DE PEDAGOGIA: RELATO DE PESQUISA
}

\author{
Nelita Ferraz de Mello Sauner
}

Professora Adjunta do Departamento de Métodos e Técnicas da Educação e Mestra em Educação pela UFPR.

\section{INTRODUÇÃO}

Este trabalho tem por objetivo avaliar o programa piloto da disciplina Concepções e Métodos de Alfabetização CMA do Curso de Pedagogia excutado nos anos de 1987-88.

Em 1987 foi realizada uma avaliação parcial, pois apenas se contava com dados fornecidos pelas expectativas (Prétestes) dos alunos de $20^{\circ}$ ano e pela percepção (Pós-testes dos alunos de 3.0 ano, egressos da disciplina.

Somente no ano seguinte, procedeu-se a coleta de dados junto aos alunos do $3 .^{\circ}$ ano que haviam sido pré-testados no ano anterior, caracterizando a pesquisa como quase experimental.

1.

DESCRIÇÃO DA PESQUISA

\subsection{Procedimentos Metodológicos}

Considerando-se a importância de que se reveste a disciplina CMA e sendo a primeira vez que essa experiência se realizaria no Curso de Pedagogia, decidiu-se elaborar e desenvolver um programa piloto para garantir a sua efetividade. 
Para avaliar o programa em questão utilizaram-se os dados co'etados durante o acompanhamento das atividades, das avaliações e reavaiiações realizadas ao longo do processo. Estes dados acumulados serviram de base para expressar o rendimento dos alunos da $1 .^{\text {a }}$ turma de Pedagog a que cursaram a disciplina CMA. Igual procedimento foi adotado em relação aos alunos das turmas A, B e CD do $3 .^{\circ}$ ano, em 1988.

Também houve necessidade de se elaborar um instrumento de testagem, de acordo com o programa piloto da disciplina, composto de quesiões objetivas e subjetivas. (V. Anexo).

O instrumento eng'obou questões relacionadas aos objetivos, conteúdos, procedimentos metodo'ógicos, recursos humanos, avaliação e outras, pertinentes à alfabetização.

Em sua fase inicial, o instrumento foi exam nado e discutido pe'as professoras responsáveis pelas turmas de alfabetização.

Em segu:da, foi validado por duas equipes de juízes: professores e alunos da UFPR.

Primeiramente, foi submetido à apreciação de sete consultores, sendo três professores do Departamento de Métodos e Técnicas da Educação, dois do Departamento de Teorias e Fundamentos da Educação e um do Departamento de Planejamento e Administração Escolar do Setor de Educação e mais um do Departamento de Lingüística, Letras Clássicas e Vernáculas do Setor de Ciências Humanas, Letras e Artes, com a finalidade de se obter dos mesmos uma validação em teermos de sua organização, abrangência e adequação à avaliação do programa. Alguns examinadores fizeram observações, sugerindo emendas ou modifcações, para a melhoria do instrumento que, devidamente examinadas e selecionadas, foram incluídas ou modificadas no orignal, quando não havia contradições entre os juízes.

Após esta fase, o instrumento foi aplicado a dez alunos do $8 .^{\circ}$ período do Curso de Pedagogia, distribuídos aleatoriamente entre as três habilitaçães: Supervisão Escolar, Orientação Educacional e Administração Esco'ar, do Curso diurno $(2 / 3)$ e do noturno $(1 / 3)$. Voltaram nove instrumentos parcialmente respondidos. 
Pelas informações desses alunas, que não tiveram a disciplina em seu currículo (semestral em extinção), verificouse que também, aos alunos do $2 .^{\circ}$ ano de Pedagoga, não se poderia aplicar o instrumento completo, ou seja, com os 28 (vinte e oito) itens. Analisadas as respostas, decidiu-se usar somente 18 (dezoito) itens.

O instrumento foi aplicado no final do mês de novembro de 1987 aos alunos de $2 .^{\circ}$ ano, ainda sem a formação em CMA, mas com expectativas em relação à disciplina para o próximo ano. Na mesma época, o instrumento completo foi aplicado aos alunos de $3 .^{\circ}$ ano que freqüentavam as três turmas da disciplina.

No final do ano de 1988 foi aplicado o instrumento completo aos alunos de $3 .^{\circ}$ ano (os mesmos sujeitos do $2 .^{\circ}$ ano de 1987), na condicão de pós-teste.

Para a organização deste modelo de pesquisa quantitativa houve necessidade de se proceder uma adaptação aos modelos propostos por CAMPBELL e STANLEY (1979: 1-138). Segue-se um esquema aue fo' d'v'dido em dois anos, pela impossibilidade de se ter nró e pós-testes com os mesmos sujeitos, no mesmo ano de 1987.

\section{FLUXOGRAMA DOS GRUPOS DE TESTAGEM *}

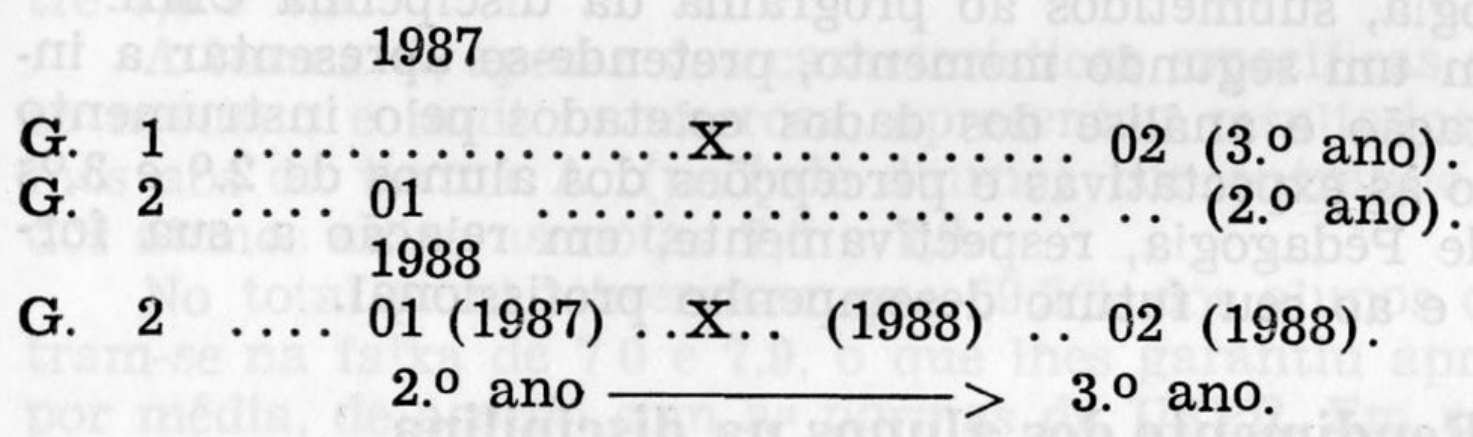

Como se observa acima esta pesquisa caractecriza-se, mais especificamente, como quase-experimental, considerando-se as suas etapas (1987-88) e a natureza dos grupos inter-dependentes e dependentes.

\footnotetext{
- CONVENÇÃo:

$\mathrm{G}=$ Grupo

$\mathrm{X}=$ Programa Piloto CMA.

$01=$ Pré-teste

02 = Pós-teste
} 


\subsection{Características da Amostra}

Para o presente trabalho o universo populaciconal foi constituído por todos os alunos regularmente matricuiados no Curso de Pedagogia, turnos diurno e noturno, semestral ou anual. (1987/88).

Para a amostra tomaram-se os 115 alunos do 2.0 ano e os 113 e 118 do $3 .^{\circ}$ ano de $1987 / 88$ respectivamente, que estavam à época da aplicação do instrumento, freqüentando o Curso de Pedagogia anual, tanto os do período diurno, como os do noturno.

Considerou-se como amostra específica para avaliação do rend'mento escolar na disciplina somente os a'unos que participaram do programa piloto de CMA, ou seja, os alunos de 3.0 ano de Pedagogia, integrantes das turmas A e B do período diurno; C e CD do noturno de 1987 e 1988, respectivamente.

\section{APRESENTAÇÃO DOS RESULTADOS}

Em um primeiro momento, pretende-se demonstrar o desempenho dos alunos das diferentes turmas dos $3.0^{\circ}$ is anos de Pedagogia, submetidos ao programa da discipclina CMA.

Em um segundo momento, pretende-se apresentar a interpretação e análise dos dados coletados pelo instrumento relativo às expectativas e percepções dos alunos de $2 .^{\circ}$ e $3 .^{\circ}$ anos de Pedagogia, respectivamente, em re'acão a sua formação e ao seu futuro desempenho profissional.

\subsection{Rendimento dos alunos na discipilina}

Para se verificar o desempenho dos alunos na disciplina tomou-se por base os resultados expressos em notas e percentuais de avaliações e reavaliações (testes, trabalhos de pesquisa, trabalhos de grupo, seminários e outros) realizadas ao longo dos anos de 1987-88.

O rendimento dos alunos de $3 .^{\circ}$ ano/87, principalmente entre as turmas A e C são bastante próximos, conforme se verifica na tabela à página seguinte: 
TABELA 01 DISTRIBUIÇÃO DOS DADOS PELAS NOTAS (RENDIMEIIO) DOS ALUNOS EM CMA, SEGUNDO AS TURMAS - 3० ANO - 1987.

\begin{tabular}{|c|c|c|c|c|c|c|c|c|c|c|}
\hline \multirow{2}{*}{\multicolumn{2}{|c|}{ NOTAS }} & \multicolumn{7}{|c|}{ TURMAS } & \multicolumn{2}{|c|}{ TOIAL } \\
\hline & & & A & $\%$ & B & $\%$ & C & $\%$ & & $\%$ \\
\hline & $\mathrm{de}$ & 5 , & & 3,2 & - & - & - & & 01 & 0,9 \\
\hline 5,1 & - & & - & - & - & - & - & - & - & - \\
\hline 6, & - & 6 & - & - & 02 & 5,1 & - & - & & 1, \\
\hline , & - & 7 & 20 & 4,5 & 16 & 0 & 31 & 2,1 & & $50=$ \\
\hline 8 & - & 8 & 0 & & 17 & & 0 & 14,0 & & 16 \\
\hline 9,0 & - & 9,9 & 03 & 9,7 & 04 & 10,3 & 06 & 13,9 & 13 & 11,5 \\
\hline OI & & & 31 & 0,0 & 39 & 100,0 & 43 & 1000 & 113 & 00,0 \\
\hline
\end{tabular}

FONTE: Elaboração da autora.

Verifica-se que mais da metade $(64,5 \%)$ dos alunos da turma A, alcançou rendimento entre 7,0 e 7,9 , seguido de $22,6 \%$ de alunos que ating ram notas entre 8,0 e 8,9 .

Na turma B, $43,6 \%$ dos alunos alcançaram notas entre 8,0 e 8,9 , e em segundo lugar, $41,0 \%$ dos alunos situam-se entre 7,0 e 7,9 .

A turma C, apesar das características específicas do curso noturno e muito numerosa, apresentou resultados próximos aos da turma A, (período diurno) concentrando $\mathbf{7 2 , 1 \%}$ dos alunos entre as notas 7,0 e 7,9.

No total geral, onserva-se que $59.5 \%$ dos alunos concentram-se na faixa de 70 e 7,9, o que lhes garantiu aprovação por média, de acordo com as normas da UFPR. Em segundo lugar, encontram-se $26.5 \%$ dns a'unos aue ating ram médias entre 8.0 e 8,9. As notas acima de 9,0 foram alcançadas por um pequeno percentual.

O rendimento do: a $a^{\top} u n a r$ do 30 ano de 1988 anresentou melhores índices como se pode verifcar na tabela 02 .

Naturalmente contou-se com alguns fatores favoráveis, tais como: maior experiência dos professores em relação à programação e adequação metodológica, maior contato do professor com os alunos, o que permitiu sentir e sanar imediata- 
mente as dificuldades, redução do número de avaliações e trabalho integrado dos fundamentos teóricos da alfabetização.

TABELA 02 DISTRIBUIÇÃO DOS DADOS PELAS NOTAS (RENDIMENTO) DOS ALUNOS EM CMA SE'GUNDO AS TURMAS - 3. ${ }^{\circ}$ ANO - 1988

\begin{tabular}{r|rrrrrrrr|rr}
\hline NOTAS & \multicolumn{7}{|c|}{} & \multicolumn{2}{|c}{ TOTAL } \\
\cline { 2 - 10 } & & A & $\%$ & B & $\%$ & CD & $\%$ & & $\%$ \\
\hline 7,0 & - & 7,9 & 12 & 32,4 & 07 & 19,4 & 09 & 20,0 & 28 & 23,7 \\
8,0 & - & 8,9 & 20 & 54,1 & 16 & 44,5 & 23 & 51,1 & 59 & 50,0 \\
9,0 & - & 9,9 & 03 & 8,1 & 10 & 27,8 & 05 & 11,1 & 18 & 15,3 \\
10,0 & & 02 & 5,4 & 03 & 8,3 & 08 & 17,8 & 13 & 11,0 \\
\hline TOTAL & $\ldots \ldots$ & 37 & 100,0 & 36 & 100,0 & 45 & 100,0 & 118 & 100,0 \\
\hline
\end{tabular}

FONTE: Elaboração da autora.

Verifica-se que mais de metade $(54,1 \%)$ dos alunos da turma A, alcançou rendimento entre 8,0 e 8,9 , seguido de $32,4 \%$ de alunos que atnigiram notas entre 7,0 e 7,9 .

Na turma B, 44,5\% dos alunos alcançaram notas entre 8,0 e 8,9 e em segundo lugar, $27,8 \%$ dos alunos situam-se entre 9,0 e 9,9 .

A turma CD, apesar das características específicas do curso noturno e mais numerosa devido ao agrupamento cios alunos, apresentou resultados seme'hantes aos das turmas do período durno: CD com 51,1\% entre 8,0 e 8,9 .

Deve-se salientar que nesse ano (1988) verificou-se notas máx ma em todas as turmas na seguinte ordem: CD com $17,8 \%$; B com $8,3 \%$ e A com $5,4 \%$.

No total geral, observa-se que $50 \%$ dos alunos concentram-se na faixa de 8,0 e 8,9. Em segundo lugar, encontramse $23,7 \%$ dos sujeitos entre 7,0 e 7,9. Porém, se forem considerados no conjunto os alunos com nota igual ou superior a 9,0 , o'tem-se um percentual maior nesta faixa, do que na correspondente às notas 7,0 e 7,9. De qualquer forma todos foram anrovados por média.

Apesar dos esforcos dos professores no sentido de neutralizar as variáveis parasitas intervenientes de 1987 (trocas de 
professores no início do período, greve com interrupção de aulas, transposição de parte do programa de $1 .^{\circ}$ para o $2 .^{\circ}$ período) ainda permaneceu, em 1988, aquela relacionada à carga horária insuficiente.

Apesar dessa limitação, contudo, pode-se concluir que o programa desenvolvido na disciplina CMA foi satisfatório, tendo em vista os resultados alcançados peios alunos nos anos de 1987/88.

Porém deve ficar claro que estes resultados (rendimento expresso em notas e percentuais) não garantem a assimilação do novo conhecimento.

Para tal assimilação seria necessário um tempo, pois o novo sempre implica a mudança de "esquemas assimiladores relativos ao objeto do conrecimento - a língua escrita - e à concepcão do processo de aprendizagem das crianças". (FERREIRO, 1990:2) e também dos adultos.

Esse tempo de assimilação do professor é um processo lento, às vezes leva muitos anos. No entanto, deve-se respeitar esse tempo para que ocorra a aprendizagem. *

\subsection{A Formação do Professor Alfabetizador: Expectativa x Percepção}

No sentido de verificar a expectativa dos alunos de $2 .^{\circ}$ ano-87 e a percepção dos de $3 .^{\circ}$ s anos $87-88$, quanto ao programa da disciplına, em relação à sua formação como professor alfabetizador, tentou-se levantar o que eles trouxeram de conhecimento específico e o que a disc.plina lhes proporcionou. Para tal, apilcou-se um instrumento constituído por 28 itens (questões abertas e fechadas), do qual foram selec:onados alguns itens que respondessem a essas indagações.

Surpreendentemente, emtora mais de $\mathbf{5 0 \%}$ dos alunos tivessem passado pela formação para o magistér o, a nível de 2.0 grau - Escola Normal ou Mag stéro (item 6, instrumento anexo) a sua grande expectativa era em relação à alfabetização, pois cerca de $80 \%$ de'es $\left(78,4 \%-2 .{ }^{\circ}\right.$ ano; $88,2 \%$ - 3.0/87 e $89,1 \%$ - 3.\%/88) declararam-se sem cocndições de alfabetizar. (item 10).

- A esse respeito consultar a teoria de aprendizagem significativa de Ausubel (MOREIRA \& MASINI, 1982). 
Esta assertiva leva a algumas reflexões: provavelmente, esses egressos não se sentem em condições de alfabetizar porque reconhecem que lhes falta um referencial teórico que lhes dê suporte para esse empreendimento. Talvez, tenham constatado que o conhecimento dos processos de alfabetização, ou as "receitas" não garantem sucesso na difícil tarefa de alfabetizar.

De qualquer maneira, é importante que reconheçam a própria fragilidade de seus conhecimentos teóricos e se proponham a um estudo sério e reflexivo, para enfrentar um trabalho de tal monta.

O quadro fica mais agravado diante da constatação de que um percentual significativo da amostra (39,5\% - 2.0/87; $53,7 \%-3.0 / 87$ e $40,0 \%-3 . \% / 88$ ) já teve experiência profissional como alfabetizador, embora essa opção tivesse sido imposta pelas escolas (itens 7 e 7.1).

A esse respeito a pesquisa de PEREIRA (1984), procurou respostas às seguintes indagações: "Por que você é alfabetizadora? Em que a sua formação para o magistério contribuiu para o trabalho de alfavetizaçao que você realiza? Onde e como aprendeu a alfabetizar?"

Tudo indica que o professor aprendeu a ser professor no seu local de trabalho, na escola, especialmente na sala de aula. Nesse espaço tardio em relação ao período de formação, é que verdadeiramente, mas de modo assistemático, ele completará o seu currículo.

Os alunos sentem essa deficiência na sua formação de $\mathbf{2 .}^{\circ}$ grau, visto que consideram a inexistência da disciplina de alfabetização ou de uma disciplina afim, como a mais grave falha do seu currículo. Por isso, viram com bons olhos a implantação da disciplina CMA no Curso de Pedagogia, pois ela é "necessária, essencial e indispensável à formação não só do alfabetizador, como do pedagogo e do educador", afirmaram a'guns. (item 11).

A questão vásica para se obter uma boa formação, na visão dos futuros profissionais foi verificada pela análise dos dados re'ativos aos sete tópicos do conteúdo da disciplina. (item 13). 
Em relação ao processo de formação do professor foram analisados aspectos essenciais a esse processo relativos às questões de conteúdo, expresso pela carga horária atribuída a cada tópico e pelo grau de especialização dos responsáveis.

$\mathrm{Na}$ seleção e organização dos conteúdos privilegiou-se, com $50 \%$ da carga horária total, os fundamentos teóricos da alfabetização: psicológicos, sociológicos e lingüísticos.

Na execução da proposta, em 1987, houve em alguns momentos a participação de especialistas de outros departamentos, setores e da Pós-Graduação em Educação e Lingüística, no sentido de garantir maior eficiência aos aspectos teóricos da alfabetização.

Os alunos do $2 .^{\circ}$ ano demonstraram grandes expectativas em relação aos conteúdos para formação do professor alfabetizador, conforme se verifica na tabela abaixo:

TABELA O3 DISTRIBUIÇÃO DOS DADOS PELOS CONTEÚDOS PARA FORMAÇÃO DO ALFABETIZADOR EM TODAS AS TURMAS, SEGUNDO AS ALTERNATIVAS - 2. ANO DE PEDAGOGIA.

1987

\begin{tabular}{|c|c|c|c|c|c|c|c|c|}
\hline \multirow{2}{*}{$\begin{array}{l}\text { Conteúdos para for } \\
\text { mação do alfabeti- } \\
\text { zador - geral }\end{array}$} & \multicolumn{6}{|c|}{ ALTERNATIVAS } & \multicolumn{2}{|c|}{ TOTAL } \\
\hline & SIM & $\%$ & NÃO & $\% \mathrm{~N}$ & $\mathrm{RE}$ & & & $\%$ \\
\hline PSICOLÓGICOS & 100 & 96,2 & 04 & 3,8 & - & - & 104 & 100,0 \\
\hline LINGƯfSTICOS & 98 & 94,2 & 06 & 5,8 & - & - & 104 & 100,0 \\
\hline SOCIOLÓGICOS & 99 & 95,2 & 05 & 4,8 & - & - & 104 & 100,0 \\
\hline COGNITIVISMO & 90 & 86,5 & 11 & 10,6 & 03 & 2,9 & 104 & 100,0 \\
\hline VARIAVEIS & 99 & 95,2 & 03 & 2,9 & 02 & 1,9 & 104 & 100,0 \\
\hline MÉTODOS & 98 & 94,2 & 05 & 4,8 & 01 & 1,0 & 104 & 100,0 \\
\hline FORMAÇÃO PROF. & 101 & 97.1 & 03 & 2.9 & - & - & 104 & 100,0 \\
\hline
\end{tabular}

FONTE: Elaboração da autora.

Em relação aos alunos de $3 .^{\circ}$ ano, os resultados podem ser observados na tabela à página seguinte. 
TABELA 04 DISTRIBUIÇÃO DOS DADOS PELOS CONTEÚDOS PARA FORMAÇAOO DO ALFABETIZADOR EM TODAS AS TURMAS, SE. GUNDO AS ALTERNATIVAS - 3.० ANO DE PEDAGUGIA.

1987

\begin{tabular}{|c|c|c|c|c|c|c|c|c|}
\hline \multirow{2}{*}{$\begin{array}{l}\text { Conteúdos para for } \\
\text { mação do alfabeti- } \\
\text { zador - geral }\end{array}$} & \multicolumn{6}{|c|}{ ALTERNATIVAS } & \multicolumn{2}{|c|}{ TOTAL } \\
\hline & SIM & $\%$ & NÃO & $\%$ & NÃO F & $\mathrm{ES} \%$ & & $\%$ \\
\hline PSICOLOGICOS & 82 & 82,0 & 18 & 18,0 & - & - & 100 & 100,0 \\
\hline LINGƯfSTICOS & 86 & 86,0 & 14 & 14,0 & - & - & 100 & 100,0 \\
\hline SOCIOLÓGICOS & 86 & 86,0 & 14 & 14,0 & 一 & - & 100 & 100,0 \\
\hline COGNITIVISMO & 68 & 68,0 & 31 & 31,0 & 01 & 1,0 & 100 & 100,0 \\
\hline VARIAVEIS & 80 & 80,0 & 19 & 19,0 & 01 & 1,0 & 100 & 100,0 \\
\hline MÉTODOS & 74 & 74,0 & 25 & 25,0 & 01 & 1,0 & 100 & 100,0 \\
\hline FORMAÇÃO PROF. & 72 & 72,0 & 25 & 25,0 & 03 & 3,0 & 100 & 100,0 \\
\hline
\end{tabular}

FONTE: Elaboração da autoria.

Os conteúdos com baixo percentual $(68,0 \%, 72,0 \%$ e $\mathbf{7 4 , 0 \%}$ ) serviram de referência para reflexão e tomada de decisão para o ano seguinte.

Quanto à percepção dos alunos de $3 .^{\circ}$ ano/88, os resulta. dos estão expressos na tabela abaixo.

TABELA 05 DISTRIBUIÇÃO DOS DADOS PELOS CONTEÚDOS PARA FORMAÇAOO DO ALFABETIZADOR EM TODAS AS TURMAS, SEGUNDO AS ALTERNATIVAS - 3.० ANO DE PEDAGOGIA.

1988

\begin{tabular}{|c|c|c|c|c|c|c|c|c|}
\hline \multirow{2}{*}{$\begin{array}{l}\text { Conteúdos para for } \\
\text { mação do alfabeti- } \\
\text { zador-geral }\end{array}$} & \multicolumn{6}{|c|}{ ALTERNATIVAS } & \multirow[t]{2}{*}{ TOTAL } & \multirow[b]{2}{*}{$\%$} \\
\hline & SIM & $\%$ & NÃO & $\%$ & NÃO $R$ & $\mathrm{~s} \%$ & & \\
\hline PSICOLOGICOS & 87 & 89,7 & 06 & 6,2 & 04 & 4,1 & 97 & 100,0 \\
\hline LINGƯfSTICOS & 84 & 86,6 & 08 & 8,2 & 05 & 5,2 & 97 & 100,0 \\
\hline SOCIOLÓGICOS & 86 & 88,7 & 07 & 7,2 & 04 & 4,1 & 97 & 100,0 \\
\hline COGNITIVISMO & 79 & 81,4 & 09 & 9,3 & 09 & 9,3 & 97 & 100,0 \\
\hline VARIÁVEIS & 84 & 86,6 & 05 & 5,2 & 08 & 8,2 & 97 & 100,0 \\
\hline MÉTODOS & 82 & 84.5 & 09 & 9,3 & 06 & 6,2 & 97 & 100,0 \\
\hline FORMAÇÃO PROF. & 84 & 86,6 & 07 & 7,2 & 06 & 6,2 & 97 & 100,0 \\
\hline
\end{tabular}

FONTE: Elaboração da autora. 
Pela análise da Tabela 05 , verifica-se que há homogeneidade em todos os conteúdos. Dos fundamentos teóricos da alfabetização, o cognitivismo de Ausubel aparece com $81,4 \%$ e os aspectos psicológicos com $89,7 \%$ sendo os percentuais minimo e máximo, respectivamente.

A formação interferiu, significativamente, nos resultados desses alunos, uma vez que eles determinaram que os conteúdos abordados foram suficientes para preparar os futuros professores em alfabetização.

Da análise dos tópicos dos conteúdos conclui-se que:

Os alunos dos $3 .{ }^{\circ}$ S anos de 1987-88 comparados entre si e também com os alunos de 2.0 ano de 1987 confirmaram a propriedade destes conteúdos e a conseqüente eficiência do programa piloto para a formação do professor alfabetizador.

\subsection{O Desempenho Profissional: Expectativa x Percepção}

No sentido de verificar a expectativa dos alunos de $2 .^{\circ}$ ano e a percepção dos de $3 .^{\circ}$ ano de Pedagogia, quanto ao seu futuro desempenho profissional, em relação ao programa desenvolvido na disciplina CMA foram analisados os itens 25 e 26 do instrumento. (V. anexo). O primeiro, quanto ao desempenho a nível de professor de $2 .^{\circ}$ grau da disciplina de Alfabetização e o segundo, seria um reforço ao Curso de Magistério, pois indagava do desempenho como professor alfabetizador, a nível de $10^{\circ}$ grau.

Em termos de profissionalização, mais de $\mathbf{5 0 \%}$ dos entrevistados já estão inseridos na força de trabalho. Dentre esses, muitos $(62,9 \%-2.0 / 87 ; 76,3 \%-3.0 / 87$ e $63,9 \%-3 . \%$ 88) atuam em escola de $1 .^{\circ}$ grau e muitos alunos de $2 .^{\circ}$ e $3.0^{\circ}$ anos já tiveram experiência em classe de alfabetização, como se viu no tópico anterior, sem ter recebido, conforme informaram, a devida preparação. Tal preparo ocorreu na prática, segundo os informantes, e comprovado na pesquisa de PEREIRA (1984: 142). 
Daí, a grande expectativa dos alunos de Pedagogia, em relação à disciplina CMA.

Os alunos de $2 .^{\circ}$ ano, segundo a Tabela 06 , apresentaram alta expectativa em relação ao seu futuro desempenho profissional a nível de $2 .^{\circ}$ grau.

Tais afirmativas dos alun.Js se baseiam no conteúdo programático da disciplina que, segundo as declarações "está completo", "engloba aspectos abrangentes, gerais e necessários à formacão do professor aliabet zador, porque dá um bom embasamento teórico, apesar de não haver prática". "Nós é que devemos aprofundar durante a vida inteira".

TABELA O6 DISTRIBUIÇÃO DOS DADOS PELO PROGRAMA PILOTO DA DISCIPLINA SE CAPACITA O PEDAGOGO PARA ASSUMIR A DISCIPLINA DE ALFABETIZAÇÃO DO CURSO DE MAGISTERIO DE 2. GRAU, SEGUNDO AS TURMAS - 2.० ANO DE PEDAGOGIA.

1987

\begin{tabular}{|c|c|c|c|c|c|c|c|c|}
\hline \multirow{2}{*}{$\begin{array}{l}\text { Programa piloto } \\
\text { capacita para } \\
\text { magistério }\end{array}$} & \multicolumn{6}{|c|}{ TURMAS } & \multirow[t]{2}{*}{ TOTAL } & \multirow{2}{*}{$\%$} \\
\hline & A & $\%$ & B & $\%$ & CD & $\%$ & & \\
\hline SIM & 21 & 75,0 & 32 & 88,9 & 26 & 65,0 & 79 & 76,0 \\
\hline NÃO & 03 & 10,7 & 02 & 5,6 & 04 & 10,0 & 09 & 8,6 \\
\hline NÃO RESPONDEU & 04 & 14,3 & 02 & 5,5 & 10 & 25,0 & 16 & 15,4 \\
\hline TOTAL & 28 & 100,0 & 36 & 100,0 & 40 & 100,0 & 104 & 100,0 \\
\hline
\end{tabular}

FONTE: Elaboração da autora.

Os a'unos de $3 .^{\circ}$ ano/87 de Pedagogia não se mostraram tão otimistas quanto ao seu futuro desempenho profissional, como se observa na tabela 07. Apresentaram como justificativas a "pouca ou falta de prática", a "necessidade de maior aprofundamento dos conteúdos" e a "pouca carga horária". 
TABELA O7 DISTRIBUIÇAO DOS DADOS PELO PROGRAMA PILOTO DA DISCIPLINA SE CAPACITA O PEDAGOGO PARA ASSUMIR A DISCIPLINA DE ALFABETIZAÇÃO DO CURSO DE MAGISTERIO DE 2.० GRAU, SEGUNDO AS TURMAS - 3.॰ ANO DE PEDAGOGIA.

1987

\begin{tabular}{|c|c|c|c|c|c|c|c|c|}
\hline \multirow{2}{*}{$\begin{array}{l}\text { Programa piloto } \\
\text { capacita para } \\
\text { magistério }\end{array}$} & \multicolumn{6}{|c|}{ TURMAS } & \multirow{2}{*}{\multicolumn{2}{|c|}{$\begin{array}{ll}\text { TOTAL } & \\
& \%\end{array}$}} \\
\hline & A & $\%$ & B & $\%$ & C & $\%$ & & \\
\hline SIM & 04 & 15,4 & 23 & 63,9 & 13 & 34,2 & 40 & 40,0 \\
\hline NÃO & 20 & 76,9 & 12 & 33,3 & 24 & 63,2 & 56 & 56,0 \\
\hline NÃO RESPONDEU & 02 & 7,7 & 01 & 2,8 & 01 & 2,6 & 04 & 4,0 \\
\hline TOTAL $\ldots .$. & 26 & 100,0 & 36 & 100,0 & 38 & 100,0 & 100 & 100,0 \\
\hline
\end{tabular}

FONTE: Elaboração da autora.

Igualmente, os alunos do $3 .^{\circ}$ ano/88 também não se mostraram tão otimistas quanto ao seu futuro desempenho profissional, conforme se verifica na tabela a seguir.

TABELA O8 DISTRIBUIÇAO LOS DADOS PELO PROGRAMA PILOTO DA DISCIPLINA SE CAPACITA O PEDAGOGO PARA ASSUMIR A DISCIPLINA DE ALFABETIZAÇÃO DO CURSO DE MAGISTERIO DE 2.० GRAU, SEGUNDO AS TURMAS - 3.०ANO DE PEDAGOGIA.

1988

\begin{tabular}{|c|c|c|c|c|c|c|c|c|}
\hline \multirow{2}{*}{$\begin{array}{c}\text { Programa piloto } \\
\text { capacita para } \\
\text { magistério }\end{array}$} & \multicolumn{6}{|c|}{ TURMAS } & \multicolumn{2}{|c|}{ TOTAI } \\
\hline & A & $\%$ & B & $\%$ & $\mathrm{CD}$ & $\%$ & & $\%$ \\
\hline $\operatorname{sIM} \ldots \ldots \ldots$ & 12 & 46,2 & 17 & 63,0 & 07 & 17,5 & 36 & 38,7 \\
\hline NÃO & 14 & 53,8 & 08 & 29,6 & 29 & 72,5 & 51 & 54,8 \\
\hline NÃO RESPONDEU & - & - & 02 & 7,4 & 04 & 10,0 & 06 & 6,5 \\
\hline TOTAL & 26 & 100,0 & 27 & 100,0 & 40 & 100,0 & 93 & 100,0 \\
\hline
\end{tabular}

FONTE: Elaboração da autora. 
A rigor, podem-se reduzir a três questões básicas as justificativas das três turmas de 1988 para a não validação do programa da disciplina CMA: tempo, conteúdo (embasamento teórico) e prática.

Este tempo refere-se a exigüidade da carga horária da disciplina, insuficiente para trabalhar e aprofundar adequadamente os conteúdos propostos. Mas também está intimamente ligado à questão do tempo de assimilação para que o aluno possa adotar a nova concepção proposta. Faltando-lhe este tempo, surge a insegurança e o receio de não conseguir atuar coerentemente com os novos princípios teóricos e fracassar em seu trabalho profissional.

O conteúdo foi estruturado tendo em vista as experiências positivas acumuladas e o êxito no emprego do conhecimento psicogenético, como capaz de reverter a situação da alfabetização, já comprovado em muitos países, além da América Latina.

Deve-se salientar que esta disciplina é de caráter teórico. A prática deverá ser feita em disciplina específica, ou seja, Prática de Ensino de $1 .^{\circ}$ e $2 .^{\circ}$ graus, em um trabalho conjunto dos professores. No entanto, este assunto pode e deve ser discutido com os professores destas duas disciplinas, a fim de sanar ou minimizar tal deficiência.

Ressalte-se que tentativas foram feitas nesse sentido: "Observação da prática pedagógica do professor alfabetizador em escola da comunidade" e discussão dessa prática, face aos métodos estudados "criticamente" e a prática feita pelos alunos, no sentido de comprovar os dados levantados nas pesquisas de FERREIRO \& TEBEROSKI (1986), com crianças da comunidade de Curitiba.

Portanto, a expectativa dos alunos de 2.0 ano de 1987 não correspondeu à percepção dos mesmos, quando egressos do $3 .^{\circ}$ ano, em 1988.

A grande diferença entre as turmas indica que a disciplina ainda não prepara, convenientemente, os alunos para o exercício profissional. Esta constatação pode ser explicada pela natureza e pelas características das próprias turmas, acrescidas de um conjunto de variáveis como: o consenso de 
diversos especialistas com abordagens metodológicas diferenciadas e a falta de tempo para a integração das novas propostas.

Assim se justif'ca, em parte, a imagem negativa da disciplina para a formação completa dos profissionais, embora as médias dos percentuais dos rendimentos nos conteúdos trabalhados nos anos de 1987-88, indicassem um bom aproveitamento.

Pela comparação dos resultados dos dois $3 .^{\circ} \mathrm{S}$ anos (1987-88) verifica-se que não houve diferença significativa entre ambos, isto é, os resultados foram semelhantes. Isto quer dizer que, assim como o programa não foi eficiente na percepção dos egressos de 1987, também não foi na dos de 1988.

Em resumo, verificou-se que a disciplina ministrada apresentou características reais inferiores à pretensão (expectativa) desses alunos.

Portanto, é perfeitamente natural e compreensível a iiisegurança dos alunos para enfrentar o trabalho com adolescentes, diante cias novidades no embasamento teórico. Porém, pela análise de outros itens, o que esses egressos necessitam é de um aprofundamento nos conteúdos trabalhados, a partir das fontes indicadas e tempo adequado à assimilação dos conhecimentos, reflexão e reelaboração para que possam administrar o seu processo de mudanças.

Os alunos de Pedagogia precisam entender que a disciplina CMA não pretende ser um receituário e sim uma reflexão crítica sobre a alfabetização, capaz de encaminhá-los a uma prática mais consciente e desafiadora.

Quanto ao item (n. ${ }^{2}$ 26) relativo ao desempenho do pedagogo como alfabetizador, os alunos do $2 .^{\circ}$ ano, segundo a Tabela 09, acreditam no seu futuro desempenho como alfabetizadores, a partir dos ensinamentos que receberão na disciplina CMA. 
TABELA O9 DISTRIBUIÇÃO DOS DADOS PELO PROGRAMA DA DISCIPLINA SE CAPACITA O PEDAGOGO PARA ASSUMIR UMA CLASSE DE ALFABETIZAÇAOO, SEGUNDO AS TURMAS 2. ANO - PEDAGOGIA.

1987

\begin{tabular}{|c|c|c|c|c|c|c|c|c|}
\hline \multirow{2}{*}{$\begin{array}{c}\text { Programa capacita } \\
\text { para alfabetização }\end{array}$} & \multicolumn{6}{|c|}{ TURMAS } & \multirow[t]{2}{*}{ TOTAL } & \multirow[b]{2}{*}{$\%$} \\
\hline & A & $\%$ & B & $\%$ & CD & $\%$ & & \\
\hline SIM & 22 & 78,6 & 32 & 88,9 & 23 & 57,5 & 77 & 74,0 \\
\hline NÃO & 03 & 10,7 & 03 & 8,3 & 07 & 17,5 & 13 & 12,5 \\
\hline NAO RESPONDEU & 03 & 10,7 & 01 & 2,8 & 10 & 25,0 & 14 & 13,5 \\
\hline TOTAL & 28 & 100,0 & 36 & 100,0 & 40 & 100,0 & 104 & 100,0 \\
\hline
\end{tabular}

FONTE: Elaboração da autora.

Em relação ao $3 .^{\circ}$ ano/87 pela tabela abaixo, apenas a turma A invalidou o programa da disciplina. As outras duas validaram-no com baixo percentual. No geral foi validado, porém com apenas $51,0 \%$.

TABELA 10 DISTRIBUIÇÃO DOS DADOS PELO PROGRAMA DA DISCIPLINA SE CAPACITA O PEDAGOGO PARA ASSUMIR UMA CLASSE DE ALFABETIZAÇAOO SEGUNDO AS' TURMAS 3. $A N O$ - PEDAGOGIA.

1987



FONTE: Elaboração da outora.

Como justificativas para tal procedimento apareceram expressões como: "faltou prática" ou "observação em classe", 
"mais embasamento teórico e metodológico ligado à prática" e "falta de tempo".

A Tabela 11 seguinte expressa a percepção dos alunos de $3 .^{\circ}$ ano de 1988 em relação ao seu preparo como alfabetizador.

TABELA 11 DISTRIBUIÇÃO DOS DADOS PELO PROGRAMA DA DISCIPLINA SE CAPACITA O PEDAGOGO PARA ASSUMIR UMA CLASSE DE ALFABETIZAÇAO, SEGUNDO AS TURMAS 3. $A N O$ - PEDAGOGIA.

1988

\begin{tabular}{|c|c|c|c|c|c|c|c|}
\hline \multirow{2}{*}{$\begin{array}{c}\text { Programa capacita } \\
\text { para alfabetizaçãe }\end{array}$} & \multicolumn{6}{|c|}{ TURMAS } & \multirow{2}{*}{$\begin{array}{r}\text { TOTAL } \\
\%\end{array}$} \\
\hline & A & $\%$ & B & $\%$ & CD & $\%$ & \\
\hline SIM & 10 & 38,5 & 19 & 73,1 & 13 & 32,5 & 45,6 \\
\hline NÃO & 13 & 50,0 & 05 & 19,2 & 22 & 55,0 & 43,5 \\
\hline NÃO RESPONDEU & 03 & 11,5 & 02 & 7,7 & 05 & 12,5 & 10,9 \\
\hline TOTAL & 26 & 100,0 & 26 & 100,0 & 40 & 100,0 & 100,0 \\
\hline
\end{tabular}

FONTE: Elaboração da autora.

Apesar dos dados pouco animadores, no geral, o $3 .^{\circ}$ ano/ 88 apresentou $45,6 \%$ de respostas afirmativas contra $43,5 \%$ de negativas. O não preparo ao desempenho profissional está ligado a falta de "tempo para maior embasamento, mais aprofundamento e aperfeiçoamento que garantisse o domínio necessário dos conteúdos estudados", "inexistência de prática", pois só "viver a teoria não é o suficiente", e "não se dá experiência vivida com a criança" e ainda a "falta de tempo".

Pela comparação dos resultados do pré e pós-testes dos mesmos sujeitos $(2.0 / 87$ e $3.0 / 88)$ quanto à formação do pedagogo como alfabetizador, verifica-se que no geral houve diferença significativa. A diferença evidencia que houve superioridade dos dados da expectativa sobre os da percepção e que o programa não capacitou o pedagogo a assumir uma classe de alfabetização a nível de $10^{\circ}$ grau. 
Em relação às turmas separadamente, somente a turma B não apresentou diferença significativa, isto é, houve uma aproximação dos percentuais entre expectativa e percepção e que o programa capacitou somente os padagogos dessa turma (B).

Comparando-se os pós-testes dos alunos de $3 .^{\circ}$ ano de $1987-88$, verifica-se que não houve diferença significativa nas turmas, isoladamente, e nem no geral, quanto à formação do alfabetizador. Em outras palavras, as respostas demonstram a equivalência da percepção de ambos os grupos, já submetidos ao programa piloto de CMA.

A diferença significativa encontrada na comparação dos grupos $\left(2 .^{\circ} \times 3 .{ }^{\circ}\right)$ era esperada. Explica-se pelas características das próprias turmas, pois os alunos do $2 .^{\circ}$ ano estavam altamente motivados, esperando o máximo possível da disciplina CMA.

Os $3 .^{\circ} \mathrm{S}$ anos de 1987-88 já tendo cursado a discicplina, constataram uma realidade modificada face a algumas variáveis intervenientes: especialistas, disciplina de cunho teórico e falta de prática, carga horária insuficiente, fazendo cair a expectativa em favor de uma percepção mais realística.

Constatando-se diferença entre expectativa e percepção é de se inferir que esses alunos se tenham tornado mais conscientes e conseqüentemente mais exigentes no que se refere ao exercício profissional em alfabetização.

3.

\section{CONCLUSÕES}

A partir da coleta e interpretação dos resultados do instrumento e dos demais dados, conclui-se que:

- O conteúdo programático proposto para a disciplina CMA corresponde não só às expectativas, como também à percepção dos alunos de 1987-88 em relação à sua formação profissional.

O programa piloto de CMA corresponde às expectativas e à percepção dos egressos da disciplina, (com algumas ressalvas) quanto ao seu futuro desempenho profissional, como professor alfabetizador, mas não corresponde como professor da disciplina de alfabetização, a nível de $2 .^{\circ}$ grau. 
A partir destas conclusões, deve-se concentrar esforços em estudar e investigar o processo de assimilação do professor PALACIO (1990:8-9) afirma que "o professor tem que primeiro desaprender, para depois voltar a aprender. Temos que saber bem como se desaprende e como se pode voltar a aprender".

Esse caminho ainda está por construir. é o desafio que ainda se tem que assumir na disciplina de CMA.

\section{REFERENCIAS BIBLIOGRÁFICAS}

1. CAMPBELL, D. T. \& STANLEY, J. Delineamentos experimentais e quase experimentais de pesquisa. São Paulo, EPU: EDUSP, 1979. 138 p.

2. FERREIRO, E. Os filhos do analfabetismo: Propostas para a alfabetização escolar na América Latina. Porto Alegre, Artes Médicas, 1990. $107 \mathrm{p}$.

3. — TEBEROSKI, A. Psicogênese da língua escrita. Porto Alegre. Artes Médicas, 1986. 284 p.

4. MOREIRA, M. A. \& MASINI, E. F. S. Aprendizagem significativa; a teoria de David Ausubel. São Paulo, Moraes, 1982. 112 p.

5. PALACIO, M. G. In: FERREIRO, E. Os filhos do analfabetismo: Propostas para a alfabetização escolar na América Latina. Porto Alegre, Artes Médicas, 1990. $107 \mathrm{p}$.

6. PEREIRA, D. B. G. A qualificação do Professor Alfabetizador e o fracasso escolar - um estudo de cáso. Curitiba, 1984. 198 p. (Dissertação de Mestrado em Educação da Universidade Federal do Paraná).

\section{A N EXO \\ UNIVERSIDADE FEDERAL DO PARANÁ SETOR DE EDUCAÇÃO \\ DEPARTAMENTO DE MÉTODOS E TÉCNICAS DA EDUCAÇÃO}

1. Data de nascimento: $\ldots \ldots / \ldots \ldots / 19 \ldots$ Idade: $\ldots . \ldots$ anos.

2. Cursa: $2^{\circ}$ ano de Pedagogia ( )

3. ano de Pedagogia ( )

3. Ingressou no Curso de Pedagogia da UFPR no ano de $\ldots \ldots \ldots \ldots$

4. Você trabalha?

1. $\mathrm{SIM}$ ( ) 
Em caso positivo, no quê?

4.1 Há quanto tempo?

5. Leciona?

1. $\operatorname{SIM}()$

2. NÃO ( )

Em caso positivo

5.1 Em que série?

$5.2 \mathrm{Em}$ que grau?

5.3 Há quanto tempo?

6. Cursou Escola Normal ou Magistério?

1. $\mathrm{SIM}($ )

7. Trabalha/já trabalhou com alfabetização?

1. SIM ( )

2. NÃO ( )

7.1 Há quanto tempo alfabetiza(ou)?

8. Por que optou pela alfabetização?

9. Como foi a experiência?

10. Saiu do curso de Magistério em condiçõęs de alfabetizar?

1. $\operatorname{SIM}($ )

2. NÃO ( )

Por quê?

11. Qual a sua opinião sobre a implantação da disciplina de Concepções e Métodos de Alfabetização no Curso de Pedagogia?

12. Considera necessário avaliar o programa piloto dessa disciplina, tendo em vista a sua reformulação ou consolidação?

1. $\operatorname{SIM}($ )

2. NÃO ( )

Por quê?

13. Os conteúdos abaixo listados são suficientes para preparar os futuros professores em alfabetização?

a) Fundamentos teóricos da alfabetização: SIM NÃO

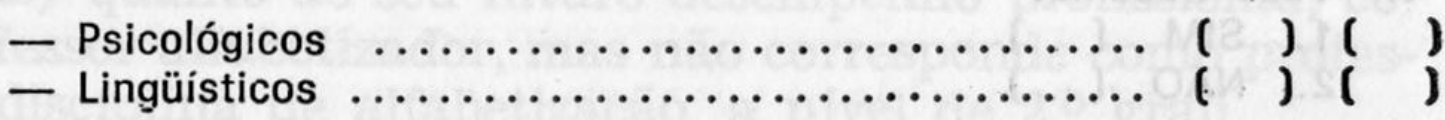


- Sociológicos

- Cognitivismo de Ausubel

b) Variáveis intervenientes na tarefa da alfabetização .

c) Procedimentos da alfabetização:

d) A formação do Professor Alfabetizador ........... ( ) ( ) a questão dos métodos

14. Os conteúdos acima listados estão na ordem em que foram trabalhados. Se você julgar que não correspondem à meihor seqüência para preparar os futuros aifabetizadores, como você modificaria a ordem proposta?

15. O tempo dedicado a cada conteúdo foi: MUITO

a) Fundamentos teóricos da

TEMPO

aifabetização:

- Psicológicos

- Lingüísticos

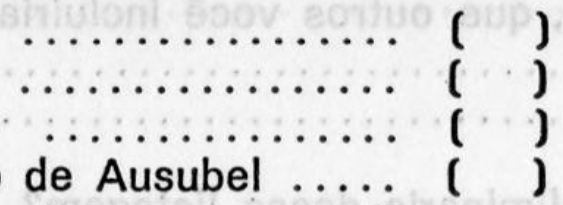

- Cocológicos de Ausubel

b) Variáveis intervenientes na tarefa da alfabetização

c) Procedimentos:

a questão dos métodos

d) A formação do Professor Alfabetizador

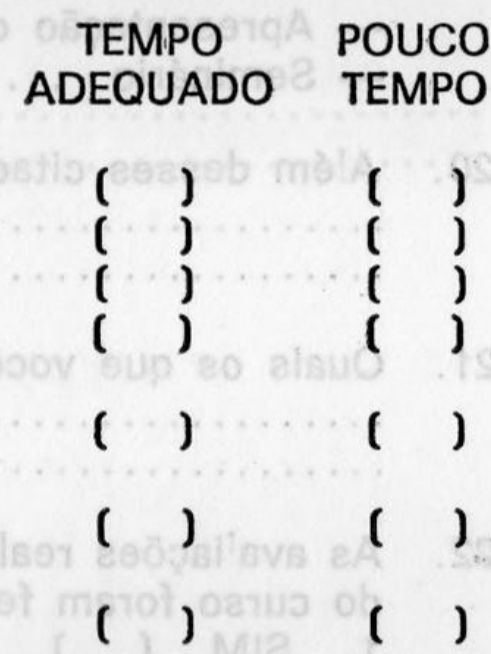

16. Você conseguiu assimilar o conteúdo? MUITO

a) Fundamentos teóricos da alfabetização:

- Psico'ógicos

- Lingüísticos

- Sociológicos

- Cognitivismo de Ausubel

b) Variáveis intervenientes na tarefa da aifabetização

c) Procedimentos:

RAZOAVEL- POUCO MENTE

a questão dos métodos

d) A formação do Professor Alfabetizador
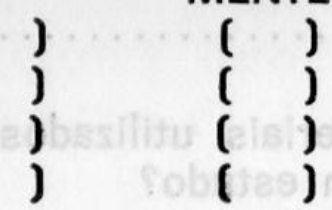

( )

$(1)$

( )

17. Qual(is) o(s) conteúdo(s) que necessitaria(m) de mais tempo?

18. Qual a carga horária você julgaria necessária para trabalhar adequadamente todos os conteúdos propostos para a disciplina? 


45 horas $($ )
60 horas $($ )
90 horas $($ )
120 horas $($ )

19. Os procedimentos metodológicos utilizados foram adequados?

- Exposição com a participação dos alunos

- Leitura e discussão de textos

- Elaboração de ensaio

- Observação da prática pedagógica do professor

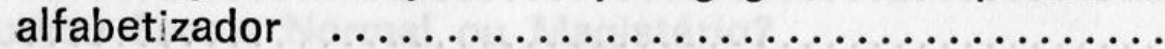

- Discussão sobre essa prática, face aos métodos

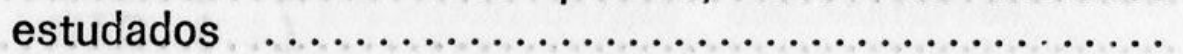

- Discussão sobre a formação do Professor alfabetizador

- Apresentação de trabalho em equipe

- Seminário

20. Além desses citados, que outros você incluiria?

21. Quais os que você eliminaria dessa listagem?

22. As ava'iações realizadas ao longo do desenvolvimento da programação do curso foram feitas de modo adequado?

1. $\operatorname{SIM}($ )

2. NÃO ( )

22.1 Se NAOO, em que conteúdo?

23. Os materiais utilizados nas aulas cobriram os conteúdos programáticos em estudo?

- livros

- textos

- dissertações

- sínteses e quadros

24. A presença de especialistas em alfabetização deve continuar para ministrar os fundamentos? . SIM NÃO

- Psicológicos .......... ( ) ( )

- Lingüísticos $\ldots . \ldots \ldots \ldots$ ( ) $($ )

- Cociológicos d......... ( ) $($ )

25. O programa piloto da disciplina capacita o pedagogo para assumir a disciplina de alfabetização do curso de Magistério de 2. Grau? 
2. $\operatorname{SIM}()$

Por quê?

26. O programa da disciplina capacita o pedagogo para assumir uma classe de alfabetização (1..$^{\circ}$ série do $10^{\circ}$ grau)?

1. $\operatorname{SIM}($ )

2. NÃO ( )

Por quê?

27. Qual foi, a seu ver, o aspecto mais positivo da disciplina?

28. Qual foi o aspecto mais negativo? 